\title{
The effect of dietary proportions of kale (brassica oleracea) and grass silage on rumen pH and volatile fatty acid concentrations in dry dairy cows
}

\section{B Keogh ${ }^{1}$, P French ${ }^{2}$, F J Mulligan}

${ }^{1}$ Waterford Institute of Technology, Waterford, Ireland, ${ }^{2}$ Teagasc Moorepark Dairy Production Research Centre, Cork, Ireland, ${ }^{3}$ University College Dublin, Dublin, Ireland

Email: bill.keogh@teagasc.ie

Introduction Ruminal $\mathrm{pH}$ is a critical factor in the normal and stable function of the rumen. A reduction in ruminal $\mathrm{pH}$ below normal $(<5.6)$ can have significant impact on microbial activity, rumen function, and animal productivity and health (Nagaraja and Titgemeyer, 2007). Forage brassicas are an alternative forage source offered to dairy cows for in - situ grazing. However, there is a scarcity of literature examining the effect of feeding diets composed of high proportions of kale (brassica oleracea) or kale alone on rumen $\mathrm{pH}$ and VFA production in the rumen.

Materials and methods In 2006/2007, an experiment was conducted at Moorepark Dairy Production Research Centre, Co. Cork. Ireland, evaluating the effect of offering differing proportions of kale and perennial ryegrass (Lolium perenne) silage on rumen physiology. Four multiparous pregnant dry dairy (100 \pm 12 days pre-partum; $600 \pm 15 \mathrm{~kg}$ of liveweight (LW)) cows permanently fitted with ruminal cannulae were randomly assigned to four kale: grass silage dietary proportions $(0: 100, \mathrm{~K} 0 ; 60: 40, \mathrm{~K} 60 ; 85: 15, \mathrm{~K} 85$ and 100:0, K100) on a dry matter (DM) basis in a 4x4 Latin Square design with four 20 day periods. Cows were acclimatised for fifteen days, followed by a five day period of experimental sampling and measurement. Internal $\mathrm{pH}$ meters were installed to continuously monitor rumen $\mathrm{pH}$ while rumen liquor collection tubes were used to sample rumen liquor for volatile fatty acid analysis at $0,4,8$ and $12 \mathrm{~h}$ after feeding on each sampling day. Cows were offered a total of $10 \mathrm{~kg} \mathrm{DM}$ of forage daily at $08.00 \mathrm{~h}$. Average intake and ruminal $\mathrm{pH}$ variables from each cow over five days of each period and from four times within each day were recorded. Analysis with mixed model procedures of SAS (SAS Institute, 2008) was used to model the correlation structure of the repeated measurements. Treatment, block effect, day and time of day were included in the model for the data as necessary structural terms and interactions were examined. An unstructured covariance model was used for the time of day (unequal spacing) and compound symmetry for the day. There was no evidence found to support more complex covariances for the effect of day.

Results The chemical and mineral composition of the kale and grass silage offered in this study are presented in Keogh et al. (2009). Cows on treatment K85 had a lower $(\mathrm{P}<0.001)$ ruminal $\mathrm{pH}$ compared to cows on treatments K100, K60 or K0 (Table 1). While a gradual decrease in rumen $\mathrm{pH}$ was observed over an eight hour period for $\mathrm{K} 85$ before recovery, offering $\mathrm{K} 100$ did not reduce rumen $\mathrm{pH}$ below 6.0 or induce acidosis (Figure 1). Increasing the dietary proportion of kale did not affect $(\mathrm{P}>0.05)$ acetate: propionate ratio production between treatments (Table 1). Cows offered K60 had increased $(\mathrm{P}<$ 0.05) rumen VFA concentration relative to K0 while offering $\mathrm{K} 85$ and $\mathrm{K} 100$ had no affect on rumen VFA concentration (Table 1). Offering dry cows K100 relative to K0 reduced dry matter intake by $17.5 \%$ (7.32 vs. $8.87 \mathrm{~kg}$ DM day ${ }^{-1}$, respectively) which may be associated with the presence S-methyl-L-cysteine sulphoxide (Barry and Manley, 1985) which can cause haemolytic anaemia and depressed DM intake.

Table 1 Effect of four pre-calving dietary proportions of kale: grass silage on dry matter intake (DMI $\mathrm{kg}^{-1}$ day), Acetic: Propionic ratio (AC:PR; $\mathrm{mmol} \mathrm{L}^{-1}$ ) and total volatile fatty acid (VFA) concentration $\left(\mathrm{mmol} \mathrm{L}^{-1}\right.$ ).

\begin{tabular}{lllllll}
\hline \hline & K100 & K85 & K60 & K0 & s.e. & P \\
\hline Kale DMI & - & 6.35 & 4.90 & - & & \\
Grass silage DMI & - & 1.71 & 3.28 & - & & \\
Total DMI & $7.32^{\mathrm{b}}$ & $8.06^{\mathrm{ab}}$ & $8.18^{\mathrm{ab}}$ & $8.87^{\mathrm{a}}$ & 0.531 & 0.05 \\
AC: PR & 3.78 & 3.86 & 3.65 & 3.71 & 0.195 & n.s. \\
Total VFA & $59.35^{\mathrm{ab}}$ & $61.74^{\mathrm{ab}}$ & $71.67^{\mathrm{a}}$ & $53.45^{\mathrm{b}}$ & 4.887 & 0.05 \\
Mean rumen $\mathrm{pH}$ & $6.26^{\mathrm{a}}$ & $5.91^{\mathrm{b}}$ & $6.32^{\mathrm{a}}$ & $6.32^{\mathrm{a}}$ & 0.05 & 0.001 \\
\hline \hline
\end{tabular}

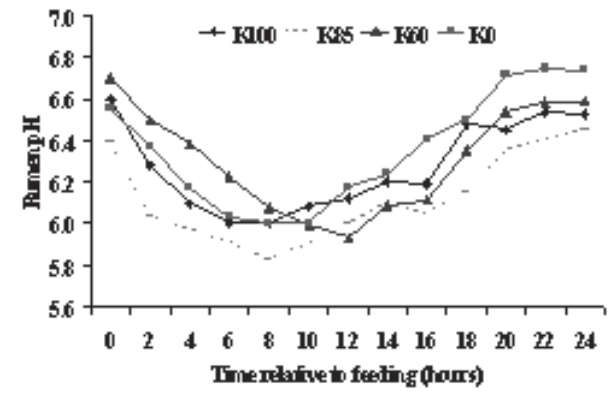

Conclusions The results suggest that increasing the dietary proportion of kale was associated with a progressive decrease in dry matter intake but with minimal effects on rumen $\mathrm{pH}$ and total volatile fatty acid concentration. The progressive decrease in dry matter intake may warrant further research on a larger scale, over a longer period of time while offered in-situ to elucidate potential effects on dry dairy cow performance.

Figure 1 The diurnal pattern of rumen $\mathrm{pH}$ in dry dairy cows offered on a DM basis four kale: grass silage

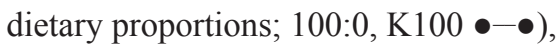

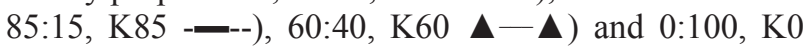
-- Feeding time was at $0800 \mathrm{~h}$.

\section{References}

Barry, T.N. and Manley, T.R., 1985. Responses to oral methionine supplementation in sheep fed kale (Brassica oleracea) diets containing S-methyl-L-cysteine sulphoxide. British Journal of Nutrition 54, $753-761$.

Keogh, B., French, P., Murphy, J.J., Mee, J.F., McGrath, T., Storey, T., Grant, J. and Mulligan, F.J. 2009. The effect of dietary proportions of kale (Brassica oleracea) and grass silage on rumen $\mathrm{pH}$ and volatile fatty acid concentrations in dry dairy cows. Livestock Science 126, 302-305.

Nagaraja, T.G. and Titgemeyer, E.C., 2007. Ruminal acidosis in beef cattle: The current microbiological and nutritional outlook. Journal of Dairy Science. 90 (E.Suppl.), E17-E 38. 